\title{
Monitoring Earthquake Shaking in Federal Buildings
}

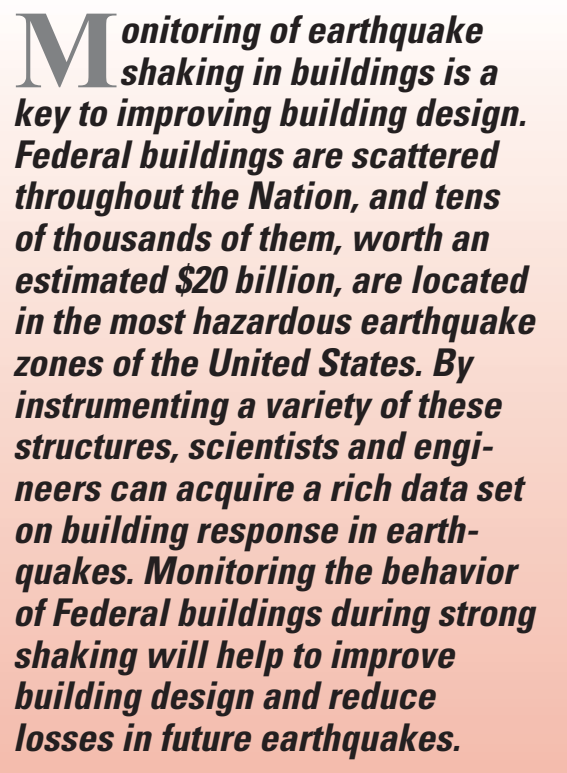

The United States Federal Government owns or leases more than 400,000 buildings, distributed through all regions of the Nation. The Government Accounting Office $(\mathrm{GAO})^{1}$ reported in 1992 that 40 percent of these buildings are in areas of significant earthquake hazard, and 20 percent are in zones where the hazard is high to very high.

${ }^{1}$ Now called the Government Accountability Office

Seismic Risk-Zone Map of 1992

Adapted from Government Accounting Office Report GA0/GGD-92-62

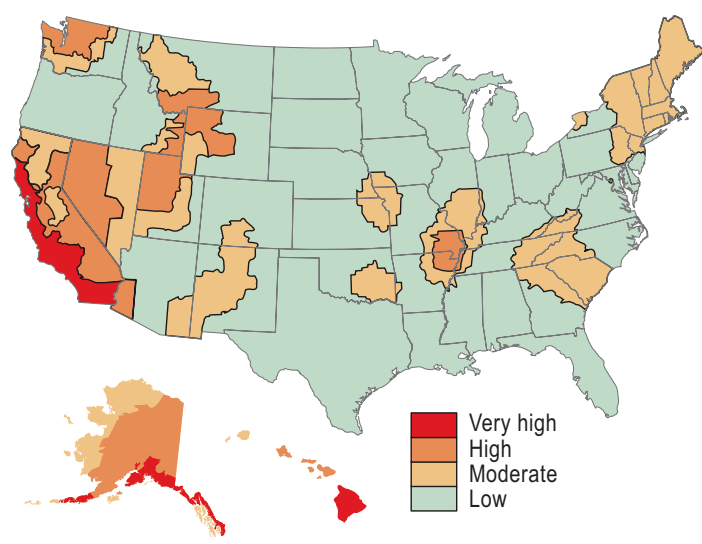

The seismic risk-zone map from the 1992 Report of the Government Accounting Office (GAO) shows the geographic spread of the earthquake hazards confronting the Nation. The GAO report found that 40 percent of Federal buildings are in areas of significant earthquake hazard, and 20 percent are in zones where the hazard is high to very high.

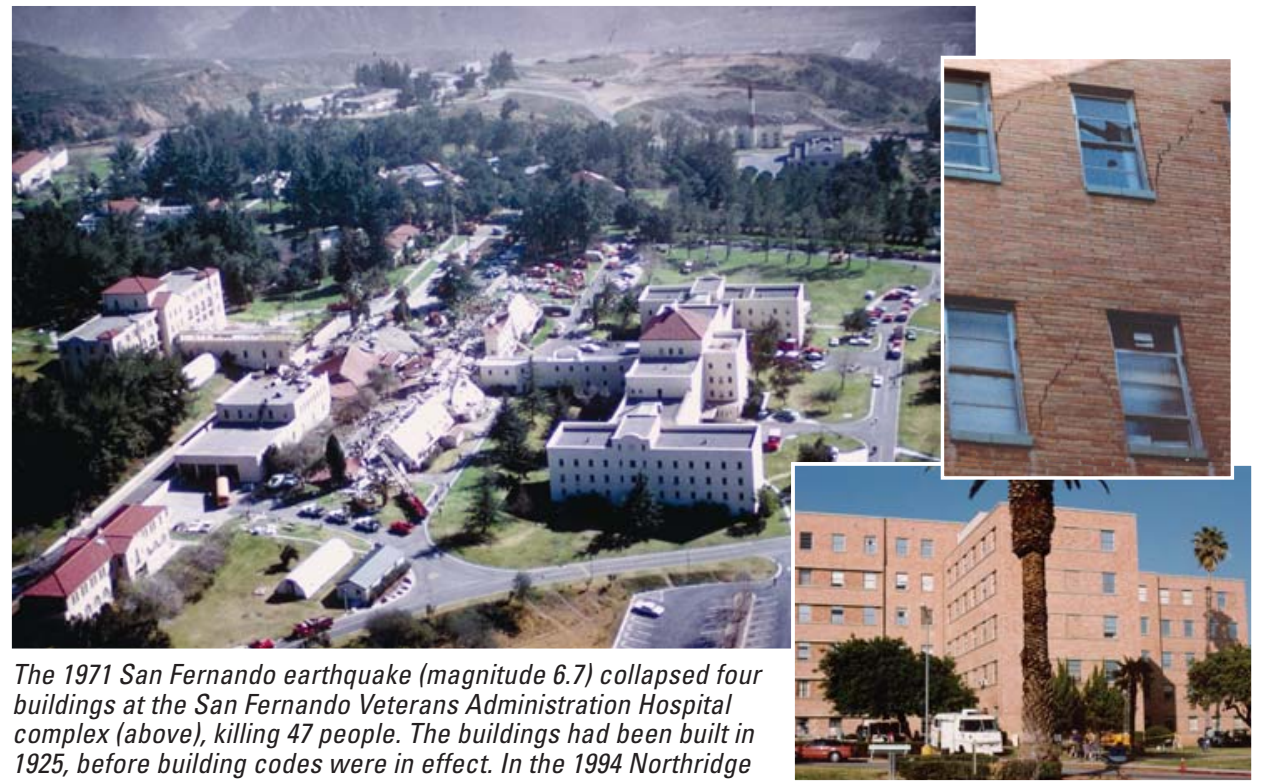
earthquake (also magnitude 6.7), a building in the Sepulveda

Veterans Administration Hospital complex (lower right), though built to code, was still damaged by strong shaking. Seismic joints separated, and building sections pounded against one another. Piers between windows cracked (upper right). Instrumenting such buildings will advance understanding of their response to earthquake shaking.

The estimated replacement value of the Federal buildings in the most hazardous earthquake zones is $\$ 20$ billion.

Although improvements in design and construction practices in the United States have markedly reduced deaths from building collapse during earthquakes, strong shaking in urban areas still causes serious damage to buildings, resulting in severe economic losses. The lower death toll in the 1994 Northridge, California, earthquake (magnitude 6.7) than in the nearby and same-size San Fernando shock of 1971 — despite the region's high population growth in the intervening decades - was largely the result of improved building design. Nonetheless, the Northridge quake still caused about $\$ 20$ billion damage to buildings in the San Fernando Valley and the Los Angeles Basin.

To improve the seismic performance of buildings, engineers need a better understanding of how existing structures respond during severe shaking. This goal requires instrumenting a large number of buildings and recording their response during strong earthquakes. The resulting data set should span the range of variability in building, site, and earthquake characteristics:

- Building characteristics - configuration, structural system, construction material, foundation type

- Site characteristics - soil properties, depth to bedrock, depth of water table, distance from quake

- Earthquake characteristics - magnitude, focal depth, type of fault, wave radiation pattern

Recordings of strong shaking in buildings allow engineers to:

- Understand how earthquake damage begins and progresses

- Evaluate earthquake-resistant design strategies

- Improve methods for predicting seismic performance

- Upgrade seismic safety provisions of building codes 
- Make informed safety decisions about reoccupancy of buildings

In an effort to provide these muchneeded recordings, scientists and engineers of the U.S. Geological Survey (USGS) and cooperating institutions are working to instrument a wide range of buildings in areas of significant seismic hazard.

Federal buildings are especially attractive targets for seismic monitoring. They are of varied sizes and configurations and are spread across all areas of seismic hazard in the Nation. In addition, in most cases they do not present some issues that impede the instrumentation of private structures, such as obtaining the required permission of a private owner. Private owners may not want buildings to be monitored for shaking out of fear of possible litigation following a damaging earthquake.

There are many advantages to placing arrays of shaking sensors in Federal buildings:

- Leading by example in gathering critical data for reducing future earthquake losses.

- Safeguarding Federal workers and the visiting public.

- Protecting the public investment in Federal buildings.

- Improving understanding of the seismic safety of new and existing, owned and leased Federal buildings, consistent with Federal Executive Orders 12699 and 12941.

Federal buildings need to be instrumented to record their response to strong ground shaking. However, not all Federal buildings can, or need, be monitored for shaking. Rather, an appropriate strategy is to selectively monitor buildings representative of the most common building types in the Fed-

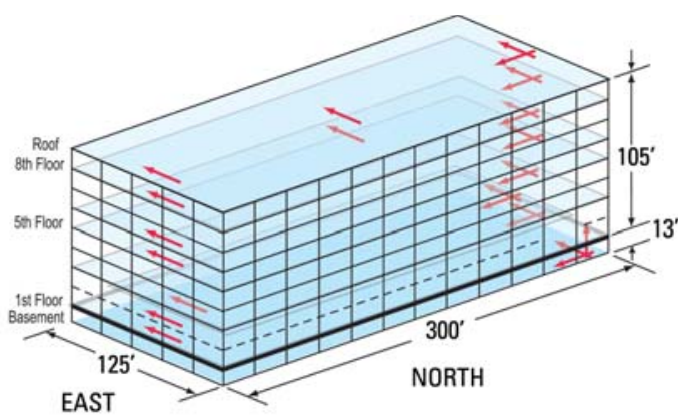

The Bennett Federal Office Building in Salt Lake City, Utah, built in 1965, underwent a major seismic retrofit completed in 2003. To reduce the shaking in the structure during strong earthquakes, the building was fitted with novel, unbonded diagonal braces and dampers (inset). Sensors have been deployed throughout the building to validate the expected improvement in seismic performance of the building during strong tremors. Red arrows indicate the locations of the sensors and show the 26 components, or directions, of motion that the sensors record.

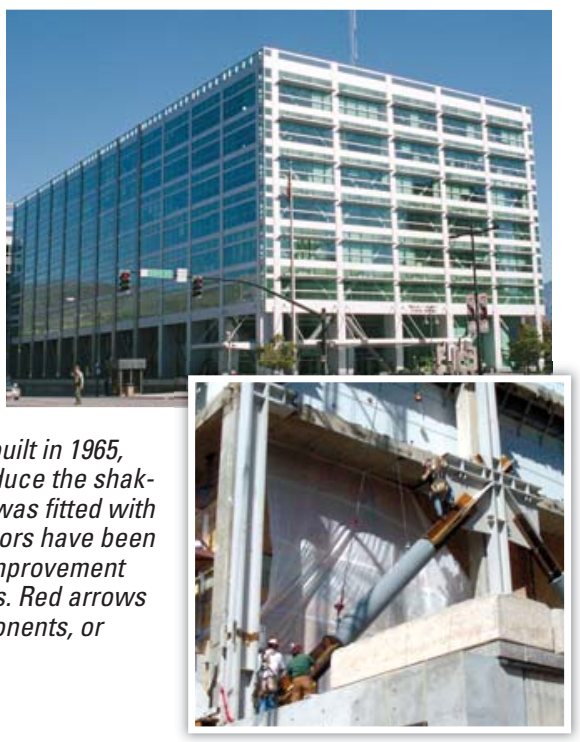

Earthquake Hazards Reduction Program (NEHRP). The results of NEHRP studies improve understanding of the earthquake loads that buildings are likely to experience and help engineers design structures more resistant to earthquakes.

The USGS - the Nation's leading earth-science agency — works closely with Federal and State agencies, regional and city governments, and private building owners to monitor earthquake shaking in buildings, as well as in bridges and dams. The pace of progress in safeguarding the Nation's building inventory against future earthquake losses can be accelerated significantly through expanded seismic monitoring of Federal buildings.

Mehmet Çelebi and Robert Page Edited by Peter H. Stauffer

Graphic design by Susan Mayfield and Judy Weathers

COOPERATING ORGANIZATIONS

Federal Deposit Insurance Corporation Federal Highway Administration General Services Administration Interagency Committee on Seismic Safety in Construction National Atmospheric and Space Administration U.S. Army Corps of Engineers U.S. Bureau of Reclamation U.S. Department of Veterans Affairs

For further information contact: Earthquake Information Hotline (650-329-4085) U.S. Geological Survey, Mail Stop 977 345 Middlefield Road, Menlo Park, CA 94025

URL http://quake.usgs.gov/research/

This Fact Sheet and any updates to it are available online at http://pubs.usgs.gov/fs/2005/3052/ 